Nóbrega S. e Colaboradora - A Erva-Doce e seu Efeito Galactógeno (Um Estudo Experimental).

Rev. Bras. Enf.; RS.36: 163 - 177, 1983.

TABELA 10 - Amamentação da criança pelo grupo amostral antes da secção do coto umbilical. Aquiraz - CE, 1982.

\begin{tabular}{cc}
\hline \hline $\begin{array}{c}\text { Amamentação/grupo amostral } \\
\text { antes da secção do coto }\end{array}$ & No. de crianças \\
\hline Sim & 03 \\
Não & 02 \\
\hline TOTAL & 05 \\
\hline
\end{tabular}

Fonte: Formulário aplicado pelas autoras

TABELA 11 - Posologia utilizada pelo grupo amostral quando da utilização do chá. Aquiraz, CE, 1982.

\begin{tabular}{cc}
\hline \hline Posologia* & Grupo Amostral \\
\hline 1 copo & 05 \\
Menos de 1 copo & - \\
\hline
\end{tabular}

TOTAL

05

Fonte: Formulário aplicado pelas autoras.

Obs.: * Posologia adotada na pesquisa - 1 copo/4 vezes ao dia.

\title{
METODOLOGIA DA ASSISTÊNCIA DE ENFERMAGEM - UMA NOVA ESTRATÉGIA DE EDUCAÇÃO EM SAÚDE
}

* Sônia Maria Passos da Silva Pinto

* Miriam Santos Paiva

$\mathrm{ReBEn}_{11} /() 6$

Silva PintoS. M. P. e Colaboradora - Metodologia da Assistência - Uma Nova Estratégia de Educação em Saúde. Rev. Bras. Enf.; RS, 36: 177-182, 1983

\section{RESUMO}

A partir da análise de programas de Assistência de Enfermagem à comunidade, já desenvolvidos, constatou-se a presença de ações puramente assistencialistas que não determinam modificações no "Status quo" e assim não produzem mudanças nos problemas apresentados pelo grupo assistido. Na

* Professores Assistentes do Departamento de Enfermagem Comunitária da Escola de Enfermagem da Universidade Federal da Bahia. 
Silva Pinto S.M.P. e Colaboradora - Metodologia da Assistência - Uma Nova Estratégia de Educação em Saúde. Rev. Bras.·Enf.; RS.36: 177 - 182, 1983.

tentativa de estabelecer uma nova abordagem nas ações de enfemagem, partiu-se para desenvolver uma metodologia de assistência capaz de transformar o nível de consciência social da população envolvida. Esta experiência está sendo implementada em um bairro periférico da Cidade do Salvador.

\section{INTRODUÇÃO}

A participação popular na identificação de suas necessidades e na busca de soluções, só ocorrerá, na medida em que, todas as pessoas estiverem conscientes de seus direitos e responsabilidades na transformação da sociedade. A participação é um instrumento democratizante e só pode ser concebida a partir das oportunidades que os indivíduos tenham de se organizar, com a intenção de interferir no processo dinâmico de mudança a que está submetida a estrutura social. Para FREIRE (4) "não há nenhuma estrutura que seja exclusivamente estática, como não há uma absolutamente dinâmica".

Em cada Sociedade podem ser consideradas duas espécies de forças antagônicas: aquela voltada para promover mudança e outra que se esforça por manter "Status quo" (3). Cabe aos profissionais da área de saúde perceberem o contronto entre estas duas forças e fazerem sua opção. Quando ele "opta pela antimudança não pode realmente interessar-se pelo desenvolvimento de uma percepção crítica da realidade por parte dos indivíduos" (4). O contrário ocorre quando o profissional opta pela mudança. Ele passa a entender a estrutura Social passível de ser transformada. Ainda é Paulo Freire (4) que nos afirma: ' $a$ mudança da percep̧̧ão da realidade, que antes era vista como algo imutável, significa para os individuos vê-la como realmente é: uma realidade histórico-cultural, humana, criada pelos homens e que pode ser transformada por eles".

Neste trabalho faz-se uma reflexão sobre programas "assistencialistas" que vinham sendo desenvolvidos em um bairro periférico de Salvador $(\mathrm{Ba})$ e propõe-se uma nova alternativa de atuação para a enfermagem, a partir da análise do impacto daqueles programas sobre a população.

O trabalho puramente assistencialista é criticado hoje por um grande número de estudiosos do assunto, porque dificulta ou mesmo impede a visualização da situação problemática que está interferindo na saúde da população. Com isto, se passa a relacionar a melhoria dos níveis de saúde, aos serviços que são oferecidos, quando se sabe que, esta só ocorrerá na medida em que se melhore a qualidade de vida (alimentação, habitação, salário, saneamento básico, dentre outros). Vale lembrar que os indicadores de saúde "apresentam forte correlação com a distribuição da renda e o nível de emprego, demonstrando (sem negar sua importância relativa) as limitaçòes do sistema médico hospitalar" (13).

$\mathrm{O}$ assistencialismo "tem sua origem na rejeição afetiva da situações de miséria em que vivem vários setores da população. A compaixão pelos pobres cria nas consciências a necessidade de viver o testemunho cristão e de praticar a caridade em favor dos necessitados dando uma resposta em termos de ajuda" (6). Atualmente a Igreja critica esta tendência e muda o seu papel para o de conscientizar os cristãos sobre sua responsabilidade de se colocarem a serviço do povo e de participarem de suas lutas.

A educação popular, incluindo a educação para a saúde, deve partir da realidade local e o profissional envolvido deve trabalhar com grupos. "A ação individual e mesmo familiar pode surgir, mas, sempre decorrente ou de apoio à ação grupal”. (6).

O trabalho grupal deve estar voltado para o desenvolvimento do grupo permitindo, desse modo, o crescimento de todos os seus integrantes. Na prática o que se observa ainda é o trabalho com lideranças naturais que foram detectadas e treinadas.

Outro ponto que deve ser considerado é a utilização de grupos como recursos para solucionar os problemas emergentes. Este é um ponto vulnerável da participação comunitária. Segundo GONÇALVES (7) esta atitude de oposição à postura paternalista, se observa em trabalhos desenvolvidos nas comunidades periféricas. Para este autor "enquanto os habitantes de bairros centrais têm as necessidades satisfeitas através do empreendimento estatal, tal grupo, já policarenciado, se assoberba ainda mais com a tarefa da resolução de tais dificuldades com seus próprios recursos".

O profissional ligado a este tipo de trabalho, deve entender que, "resolver os problemas de uma determinada comunidade unicamente através de um melhor aproveitamento de seus próprios recursos traduz a concepção de que os problemas locais são locais não somente em sua expressão como em sua origem" (11). Esta é uma visão simplista que pretende levar os grupos da população a assumir uma nova postura diante de sua condição, utilizar melhor os seus recursos e se integrar dentro da estrutura social vigente. Ao contrário, o enfoque histórico estrutural nos indica que a prática dos profissionais deve se voltar para a expressão dos vários setores da sociedade, "para que no confronto de interesses com outros grupos sociais possam influir no contínuo processo de mudança por que passa a estrutura social” (11).

No primeiro enfoque acima mencionado o indivíduo é um ser de adaptação ao mundo histórico cultural e a "ação educativa se processa em termos mecanicistas, o que resulta uma cada vez maior domesticação do homem" (5). Se ele é considerado "um ser de transformação do mundo" o processo educativo 
Silva Pinto S.M.P. e Colaboradora - Metodologıa da Assistência - Uma Nova Estratégia de Educação em Saúde. Rev. Bras. Enf.; RS.36: 177 - 182, 1983.

será cada vez mais libertador (5). Esta última hipótese levaria à educação verdadeiramente humanista, em que o homem deixaria de ser considerado "coisa" ou expectador passivo de sua realidade, para se tornar sujeito da mudança desta realidade. Deste modo considera-se que "o homem deve ser o sujeito de sua própria educação. Não pode ser o objeto dela. Por isso ninguém educa ninguém” (4).

Deve ser lembrado ainda que a educação é um processo permanente e que o educador deve se colocar como comunicador de "um saber relativo a outros que possuem outro saber relativo" (4).

Para MELO (9) ainda hoje "a educação em saúde fica à margem da relação concreta técnicopopulação frente à realidade onde se dão as relações com o meio. Dessa maneira, é reduzida a simples agente de informação ou propaganda, distribuindo noções de higiene e regrando a vida da população".

$\mathrm{O}$ pessoal de enfermagem desempenha, dentre suas áreas básicas, atividades de educação em saúde. A depender da forma como o ser humano é visto por estes profissionais, estas atividades poderão ser mais “domesticadoras" ou "libertadoras". Resta questionar como vem sendo desenvolvida esta prática. Estará ela relacionada com a transmissão de informações? ou estará atuando como fator de transformação? A resposta a estas questões deve ser dada por cada profissional, a partir de uma reflexão sobre a metodologia que vem utilizando. Aquele que enfatiza a participação comunitária como fundamental para o desenvolvimento das atividades educativas, certamente vem alcançando êxito no desenvolvimento dos programas.

A participação comunitária nos vários níveis do processo educativo é preconizada pela maioria dos autores e deve ser permitida e estimulada pelos profissionais, como fundamental importância para a mudança da estrutura vigente. Vale lembrar que esta participação deve ser exercida ativamente, ao contrário do que se observa em muitos projetos de Saúde e projetos educativos, quando a comunidade participa de forma passiva.

Participação "passiva" é quando os técnicos decidem tudo e desenvolvem ações que são absorvidas passivamente pelos beneficiários. Aos primeiros cabe conquistar a participação, no sentido de que os últimos aceitem o que lhes é oferecido e os programas surtam algum efeito (10). Neste caso, as massas marginalizadas são levadas a adaptar-se à realidade. A participação "ativa", ao contrário, visa a libertação do homem. Para NORONHA (10) a participação comunitária deve ser "entendida agora como participação das classes populares visando uma melhoria das condições de saúde destes grupos".

Deve-se questionar o processo educativo quando a saúde constitue sua finalidade. É como aponta CARVALHO (1) "o que se verifica de inicio é que, sob o ponto de vista do agente, a saúde pode ser tomada como instrumento ou como finalidade do processo educativo. No primeiro caso a educação é o objetivo central, enquanto os problemas de saude constituem o terreno a partir do qual esse objetivo se concretiza. No segundo caso, o objetivo se prende à obtenção de melhorias no nível de saúde da comunidade e a prática educativa é uma forma de viabilizar esse objetivo, ou seja de conferir maior eficácia ao combate à doença". O segundo objetivo é o ponto chave da maioria dos programas de medicina comunitária "o que faz destes programas meros instrumentos de reiteração de uma situação de dominação" (10).

Finalmente, de referência à participação da comunidade deve-se favorecer, em primeiro lugar, as varias formas de expressão dos indivíduos. Só a partir da organização popular quando os grupos passam a tomar conhecimento de sua condição concreta, a tentar solucionar alguns de seus problemas, aprofundando a reflexão sobre os obstáculos que se antepõem à solução e encontrando, a cada momento, novas formas de organização e mobilização necessárias para um determinado nível de ação, é que poderão as classes populares iniciarem seu processo de participação. "É a partir dessa participação, de uma tomada de consciência crescente na luta pela solução do conjunto de seus problemas, que podem se garantir as condições de uma verdadeira participação setorial". (10).

\section{DESENVOLVIMENTO}

Para fins de melhor compreensão, dividiu-se o trabalho em duas partes. Na primeira fez-se uma reflexão sobre o programa que vinha sendo desenvolvido no bairro de Pau da Lima, desde 1976 . $\mathrm{Na}$ segunda parte analisa-se a outra metodologia que utiliza uma nova estratégia de educação em saúde.

1.1. Programa de assistência de enfermagem à gestante.

Em determinado momento histórico, marcado pelas inúmeras preocupações de enfermeiros na busca de metodologias de assistência de enfermagem, voltadas para o atendimento das necessidades humanas básicas, iniciou-se um trabalho assistencial de enfermagem para gestantes sadias em um bairro periférico da Cidade do Salvador (Ba). Isto ocorreu em 1976, quando a Escola de Enfermagem da UFBA foi convidada, a desenvolver um programa educativo, dirigido às mães matriculadas para receber suplementaçãoalimentar. 
Silva Pinto S.M.P. e Colaboradora - Metodologia da Assistência - Uma Nova Estratégia de Educação em Saúde. Rev. Bras. Enf.; RS.36: 177 - 182, 1983.

A partir deste convite elaborou-se uma programação estruturada, com objetivos predeterminados, sem nenhuma preocupação com as aspirações das clientes.

O programa educativo tinha como clientela gestantes, nutrizes e menores até seis anos. A maioria das gestantes não contava com assistência pré natal, o que levou à organização de um Serviço Assistencial para gestantes sadias. Desse modo partiu-se para um trabalho eminentemente assistencialista, incorporando neste, o processo educativo, na tentativa de atender às necessidades individuais de cada gestante.

Como em todo trabalho assistencialista, visava-se encontrar saídas imediatas e individuais para os problemas que se apresentavam no momento, constituindo-se um paliativo para as situações evidentes, na maioria das vezes reflexo de uma problemática bem mais ampla. Com este modelo mitificava-se a realidade o que, conseqüentemente, impossibilitava que esta se revelasse não só para os técnicos como para as próprias mães.

Não se valorizava a prática de enfermagem moldada na realidade local existente, embora esta realidade já fosse parcialmente conhecida a partir de levantamentorealizado (12).

Como toda a periferia dos Centros urbanos o bairro em foco apresenta algumas características peculiares. Fica localizado entre duas prisões e, em 1967, a maioria das famílias dos presidiários aí se estabeleciam. Bastante acidentado, não conta com infra-estrutura de saneamento básico e a rêde elétrica é insuficiente. Os estabelecimentos comerciais e industriais são de pequeno porte e absorvem mão de obra local. $\mathrm{O}$ atendimento à saúde é realizado, principalmente, por serviços isolados, na maioria particulares, que não atendem às necessidades da população. As escolas são em número insuficiente, o que levava as mães a recorrerem às professoras particulares, residentes no bairro, algumas vezes sem formação pedagógica, acarretando com mais esta despesa o orçamento doméstico. $\mathrm{O}$ transporte coletivo é deficiente, dificultando o acesso ao Centro da Cidade.

Como ocorre nos bairros periféricos dos grandes Centros, sua população vive na chamada "marginalidade urbana", fruto da urbanização acelerada decorrente das migrações. Como tal, esta é entendida como "processo que decorre de formas pecualires de inserção no sistema produitivo" (8), o que contribui para o baixo poder aquisitivo e para a participação do trabalho autônomo no setor terciário da economia, desenvolvendo atividades de vendedores ambulantes, serviços de reparação e conservação, vigilância, limpeza e carga, empregos domésticos, bem como um conjunto variado de atividades mal definidas cujo executor pode ser designado de "tarefeiro" (8). Proveniente de várias localidades do interior, as famílias aí se fixaram em busca de novas oportunidades para melhoria de vida.

A assistência de enfermagem desenvolvida neste contexto social, baseava-se na consulta de enfermagem que, como atividade individualizada, visa identificar problemas de enfermagem, levantando e implementando soluções para os mesmos. Esta metodologia, utilizada de forma isolada, pouco ou quase nada pode fazer para despertar nos indivíduos a compreensão de seu papel como ser histórico e, por isso mesmo, capaz de influenciar na transformação da sociedade.

Analisando-se o impacto provocado por este programa nas gestantes assistidas, observou-se que estava bem mais relacionado à aquisição de alimentos - necessidade sentida pelas mães - do que mesmo à assistência que vinha sendo prestada - necessidade sentida pelos profissionais. Isto foi verificado pela queda da demanda ao serviço, quando a suplementação alimentar foi retirada, a partir de uma redistribuição, das áreas prioritárias, pelo órgão oficial responsável.

Embora o processo educativo estivesse incorporado na metodologia desenvolvida, não se notou a influência deste sobre a população assistida no que se refere à mudança de comportamento. Vale ressaltar que, embora as gestantes tivessem sido colocadas como centro do processo educativo, não foram, em nenhum momento, estimuladas a participar deste processo. Isto talvez tenha contribuído para que elas não se mostrassem sensibilizadas para a importância da assistência pré-natal.

\subsection{A nova alternativa de educação em saúde}

A partir da reflexão desenvolvida anteriormente, sentiu-se a necessidade de tentar uma nova alternativa. Considerando-se que a realidade só pode ser modificada pelo próprio homem, optou-se por um trabalho com maior participação social. Segundo recomendação da Conferência Internacional de Alma - Ata (2) as comunidades devem ser incentivadas a assumir a responsabilidade por sua saúde e bem estar, necessitando, para tanto, de participar na avalia- 
Silva Pinto S.M.P. e Colaboradora - Metodologia da Assistência - Uma Nova Estratégia de Educação em Saúde. Rev. Bras. Enf.; RS.36: 177 - 182, 1983.

ção da situação, na definição de problemas, na fixação de prioridades, no planejamento de atividades relacionadas aos cuidados primários e, finalmente, na execução de tais atividades.

Para iniciar o trabalho, entrou-se em contato com outros profissionais e membros da paróquia local, que também desenvolviam atividades isoladas na área. Após várias discussões ficou evidenciado que, grande parte das tentativas até então implementadas, não haviam alcançado êxito. Desse modo surgiram novas propostas de ação.

1.2.1. Delimitação da área

Para desenvolver o trabalho, escolheu-se uma das inúmeras invasões do bairro denominada Jardim Guiomar, que até o momento não havia sofrido intervenção de técnicos de qualquer natureza. Vale ressaltar que o local não contava com nenhuma forma de organização e apresentava características semelhantes as já mencionadas para o bairro, com o agravante de ser de difícil acesso pela sua localização.

1.2.2. Recursos financeiras

Com o objetivo de se obter recursos enviou-se o projeto ao Conselho Nacional de Desenvolvimento Científico e Tecnológico (CNPq), que concedeu o financiamento necessário.

\subsubsection{O trabalho de mobilização}

Contando com a participação de jovens do bairro o grupo, agora ampliado, resolveu construir um barraco de madeira que serviria para atividades de interesse dos moradores.

Iniciou-se então a primeira etapa do trabalho que constou de visitas às famílias do bairro, com o objetivo de levantar subsídios sobre a realidade local, como também de entrar em contato com os grupos informais existentes e de conhecer as pessoas e os papéis por elas desenvolvidos.

Nestas visitas, aproveitou-se para informar sobre o trabalho que seria iniciado, despertando nos moradores, a necessidade de sua participação na busca e solução de seus problemas de saúde. Pressupunha-se com isto que, havendo um real envolvimento e participação da comunidade nas etapas de elaboração e implantação da nova estratégia, mais positivos seriam os resultados.

A partir de dados levantados nestas visitas chegou-se à conclusão que era prioritário para os moradores, dentre outras necessidades identificadas, a implementação de programas de assistência para crianças e gestantes. Estes programas diferem daquele anteriormente desenvolvido na primeira etapa do trabalho, na medida em que, partiram da solicitação da comunidade. Isto ficou comprovado pela demanda ao serviço, o que será analisado em trabalho futuro. Por outro lado, estes programas visam principalmente, a mobilização social.

Concomitante a estes programas, iniciou-se o trabalho educativo, bastante informal, através de discussões, aproveitando a presença das mães no barraco e partindose de temas levantados no momento. Estas discussões tinham como finalidade sensibilizar as mães sobre a importância de sua participação, como fator preponderante para mudança da realidade local. A partir deste trabalho surge um clube de mães, organizado pela própria comunidade e tendo como local de encontro o barraco que, começa a atingir sua finalidade.

Desponta, deste modo, ainda de forma bastante incipiente, um tipo de organização popular. É interessante observar-se que, ao lado do clube de mães, surge uma associação de moradores, predominantemente masculina e que, no momento, só desenvolve atividades esportivas.

Até então não se considerou oportuno a intervenção de enfermagem nestes grupos, mantendo-se, no entanto, uma atitude de expectativa, aguardando a maturação do processo porque passam aqueles grupos, respeitando-se, desse modo, a situação, o ritmo e o nível dos mesmos.

\subsubsection{Levantamento de problemas da comunidade}

Com a finalidade de levantar, de forma mais sistematizada, os problemas da comunidade, está se utilizando um instrumento estruturado com algumas famílias da 
Silva Pinto S.M.P. e Colaboradora - Metodologia da Assistência - Uma Nova Estratégia de Educação em Saúde. Rev. Bras. Enf.; RS.36: 177 - 182, 1983.

área. Para tanto, foi feito um cadastramento inicial dos moradores de uma área delimitada do Jardim Guiomar, correspondente a trezentos e dez barracos. Estes foram tomados como universo para a pesquisa, do qual se retirou, de forma aleatória, a amostra de $30 \%$. Este diagnóstico está em fase de coleta de dados que depois de apurados, serão analisados com a Comunidade, na perspectiva de um plano de ação.

\section{CONCLUSÕES}

Este estudo consistiu de uma análise sobre a implementação de um programa de assistência de enfermagem a gestantes, em um bairro periférico de Salvador numa linha assistencialista. Considera-se que, programas desta natureza, não exercem influência sobre a realidade global, favorecendo a manutenção do "Status quo", como também dos fatores que interferem nas condições de saúde da população. Após esta análise foi proposta uma alternativa de educação em saúde, a partir da mobilização da comunidade, visando sua participação em todas as etapas do processo educativo, para melhoria das condições de saúde. Esta segunda fase está sendo desenvolvida em uma "invasão" do mesmo bairro, denominada Jardim Guiomar.

Conclui-se que esta é uma das alternativas viáveis, em programes desta natureza, tendo em vista, o impacto que vem exercendo sobre a população local.

\section{SUMMARY}

The analysis of developped programs of Nursing Assistance given to the community has revealed the existence of merely "assistantialist" actions, which do not determine any modification in the "Status quo" and, therepore, do not cause any change in the problems presented by the group that had been attended. As an attempt at establishing a new approach to the nursing practice, it was decided hat a Kind assistance methodology should be applied, which would be capable of changing the level of social awareness on the part of the group involved. Such an experiment has been implemented in the outskirts of Salvador.

\section{REFERÊNCIA BIBLIOGRÁFICA}

1. CARVAlho, A. J: - Saúde e Educação de Base. Saúde em Debate, (7/8): 61-65, abr./jun. 19.78.

2. CONFERÊNCIA INTERNACIONAL SOBRE CUIDADOS PRIMÁRIOS DE SAÚDE, Alma-Ata, URSS, 6-12 de setembro de 1978. Cuidados primários de saúde. Brasília, OMS/UNICEF, 1979, $64 \mathrm{p}$.

3. FOSTER, G. M. - A dinâmica da mudança: cultura, sociedade, psicologia e economia. In: As culturas tradicionais e o impacto da tecnologia. Rio de Janeiro, Fundo de Cultura, 1962. p. 61-65.

4. FREIRE, P. - Educação e mudança, 4..ed. Rio de Janeiro, Paz e Terra, 1981. 79 p.

5. -Uma educação para liberdade - 4. ed. Porto, Dinalivro, $1974.68 \mathrm{p}$. (Textos marginais, 8).

6. FURTADO, D. B. - Ação de Base em Educação Popular - cadernos do CEAS (77): 49, jan/fev. 1982

7. GONÇALVES, A. - A saúde e população: contribuição para o entendimento deste binômio em nosso meio. Ciência e Cultura, 33 (11): 1425-1429, novembro. 1981.

8. KOVARICK, L. - Capitalismo e Marginalidade na América Latina. 2. ed. Rio de Janeiro, Paź e Terra, 1977: $188 \mathrm{p}$.

9. MELO, J. A. C. - A prática da saúde e a Educação. Saúde em Debate, (1): 13-14, out/dez. 1976.

10. NORONHA, J. O. C. \& CRAVASSOS, C. M. Participação comunitária nos programas de saúde. Saúde em Debate, R. de Janeiro, 12: 18-20, 1981.

11. PELLEGRINI FILHO, A. A medicina comunitária, a questão urbana e a marginalidade social. In: Saúde e Medicina no Brasil: Contribuição para um debate. Rio de Janeiro, Graal, 1978. p. 207-24.

12. PINTO, S. M. P. da S. \& PAIVA, M. S. Consulta de enfermagem à gestante. In: REUNIÃO DE ENFERMAGEM MATERNO INFANTIL DA BAHIA, 1., Salvador - outubro de 1978. Anais... Salvador, ABEN, 1978 - p. 88-93

13. VIANA, S. MAGALHÂES - Política Social no Brasil, 1978 (mimeografado) 